\title{
Risk Factors and Prevalence of Soil-transmitted Helminth Infections
}

\author{
Ida Bagus Yorky Brahmantya ${ }^{1}$, Haikal Hamas Putra Iqra ${ }^{1}$, I Gusti Ngurah Bagus Rai Mulya Hartawan ${ }^{1}$, Ida Ayu Widya Anjani ${ }^{1}$, \\ I. Made Sudarmaja ${ }^{2 \star}$, Christopher Ryalino ${ }^{3}$ \\ ${ }^{1}$ Undergraduate Student, Faculty of Medicine, Udayana University, Bali, Indonesia; ${ }^{2}$ Department of Parasitology, Faculty of Medicine, \\ Udayana University, Bali, Indonesia; ${ }^{3}$ Department of Anesthesiology, Faculty of Medicine, Udayana University, Bali, Indonesia
}

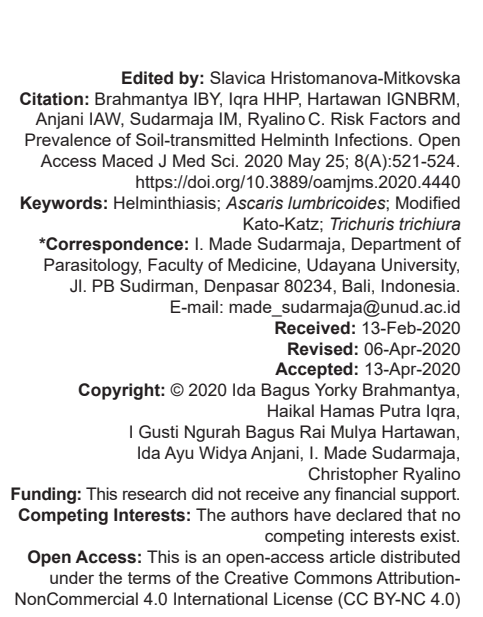

Abstract

BACKGROUND: Soil-transmitted helminths (STHs) infection is an infectious disease that has a high prevalence with unclear clinical symptoms and predominantly affects children in the age range of 5-14 years.

AIM: This study aims to determine the prevalence and risk factors for STH infections in elementary school students in an STH endemic area.

METHODS: This study was an observational analytic study with a cross-sectional design with a total sampling method. Risk factors were obtained by a questionnaire, and the diagnosis of STH infection was established through a fecal examination with the modified Kato-Katz method. The data are then processed and analyzed using the SPSS application. Chi-square test and risk assessment are used to determine risk factors for STH infection.

RESULTS: A total of 138 children participated in this study. The prevalence of STH infections obtained was $56.5 \%$ with Trichuris trichiura (53.8\%), Ascaris lumbricoides (18\%), and both $(28.2 \%)$ as etiology. The degree of STH infection varies from mild-to-severe. All risk factors related to hygiene and sanitation have a statistically significant relationship with the prevalence of STH infections. Eating while playing on the ground was the most influential risk factor for the high prevalence of STH infections ( $p<0.001, \mathrm{PR}=2.611, \mathrm{Cl} 95 \%=1.961-3.477$ ).

CONCLUSION: The prevalence of STH infections in elementary schoolchildren in Tenganan village was $56.5 \%$. Low personal hygiene and sanitation are risk factors for STH infection that can be overcome; therefore, it is necessary to introduce early prevention efforts in elementary schoolchildren as one risk group for STH infection.

\section{Introduction}

Soil-transmitted helminths (STHs) infection is one of the world's health problems that received less attention (neglected disease) [1]. STH infection is often associated with areas that have tropical climates, low community hygiene, lack of access to clean water, and lack of sanitation adequate [2]. Based on data from the World Health Organization (WHO), it shows that more than 1.5 billion or $24 \%$ of the world's population is infected with STH with the most significant number being in SubSaharan Africa, America, China, and East Asia. More than 267 million pre-schoolchildren and more than 568 million school-aged children are infected with STH and need curative and preventive measures [3]. The prevalence of intestinal worms in Indonesia alone reaches 45-65\% with the highest incidence in children aged $<12$ years [4].

Bali is one of the areas with a high prevalence of STH infections in the population group of pre-school and schoolchildren [5]. Another study reported that as many as $30 \%$ of elementary school students were positively infected by STH from 2004-2014, with the most common worms were Trichuris trichiura and Ascaris lumbricoides [6].
STH infections generally infect populations of school-age and pre-schoolchildren. Both of these population groups are very susceptible to worm infections, which are often not detected. STH infections typically have a very low mortality rate but cause morbidity that can affect a person's quality of life for a long time. One of the manifestations in children is in the form of symptoms of nutritional deficiencies, anemia, developmental disorders, and impaired development of children's cognitive functions [7], [8]. This can affect children's intelligence and interfere with children's education.

One of the global targets of the World Health Organization (WHO) in 2020 is to eliminate all morbidity caused by STH infections in children. The strategy is to recommend periodic administration of antihelmets without making a diagnosis to the entire population of children living in endemic settings [3]. However, reinfection often occurs after medical treatment has been completed. This is because STH transmission is influenced by personal and environmental aspects, including the habit of not washing hands before eating, outside activities barefoot, nail-biting, poor sanitation, and inadequate water sources, which facilitates transmission from one individual to another [9]. 
This study aims to determine the prevalence and risk factors for STH infections in elementary school students in an STH endemic area. We collected the data for this study from Tenganan village at Karangasem Regency (Bali Island, Indonesia) which is one of the areas with a high STH infection and has been given mass antihelminthic drug administration by the government.

\section{Methods}

This study was an observational crosssectional analytic study conducted in September 2018. We collected the data from all elementary schoolchildren in Tenganan village. The sampling technique used in this study was total sampling. All parents and/or legal guardians of the students provided a written informed consent to be included in this study. Stool samples were then collected from all subjects to be examined at the Laboratory of Parasitology, Faculty of Medicine, Udayana University. The study protocol was approved by the Institutional Review Board.

Stool specimen collection is carried out using a $10 \mathrm{ml}$ stool pot that has been labeled with the name of an elementary student. Stool specimens are collected a day after the stool pots are distributed. The specimen is then sent to the parasitology laboratory for examination. Stool specimen examination is carried out by a trained analyst with the modified Kato-Katz method and then observed under a microscope. This fecal specimen examination is used to determine the status, type, and degree of STH infection of Tenganan Elementary School 2 and 3 students. The method used to determine the degree of STH infection is to count the number of eggs per gram (EPG) of stool for each type of worm in the entire field of view (FOV). Then, the calculation results are adjusted to the classification of the degree of infection by the WHO.

After submitting fecal pots, all students were interviewed related to the risk factors possessed by helminthiasis using a questionnaire. The validated questionnaire contained 14 questions regarding the sanitation of elementary school students as risk factors for helminthiasis, including washing hands habits, soil contact, nail-cleaning habit, restrooms availability, and consuming worm medication.

Demographic data, answers to the questionnaire, and results of the examination of fecal specimens were processed and analyzed using the SPSS for Windows. Chi-square analysis was used to find the relationship between risk factors based on questionnaire answers and worm status owned by elementary school students. The results of the study were considered statistically significant for $p<0.05$.

\section{Results}

A total of 138 students with a median age of 9 were enrolled for this study. The characteristics of the subjects are presented in Table 1. STH infections tend to be spread evenly in every age group, as displayed in Figure 1.

Table 1: Subjects' characteristics

\begin{tabular}{ll}
\hline Variables & $\mathrm{n}=138$ \\
\hline Sex & $68(49.3)$ \\
$\quad$ Male, $\mathrm{n}(\%)$ & $70(50.7)$ \\
Female, $\mathrm{n}(\%)$ & \\
STH infection & $78(56.5)$ \\
Positive, $\mathrm{n}(\%)$ & $60(43.5)$ \\
Negative, $\mathrm{n}(\%)$ & \\
Positive parasites & $42(53.8)$ \\
$\quad$ T. trichiura & $14(18.0)$ \\
A. lumbricoides & $22(28.2)$ \\
Both &
\end{tabular}

The EPG count revealed mild infection in 37 students $(88.1 \%)$ and moderate infection in 5 students $(11.9 \%)$ infected with Trichuris trichiura. We also found mild infection in 10 people $(71.4 \%)$ and severe in 4 people $(28.6 \%)$ students infected with Ascaris lumbricoides. In mixed infections, the degree of infection obtained, as described in Table 2. Based on the results of the Chi-square analysis (Table 3), no significant relationship was found between sex and STH infection status. However, all of the suspected risk factors had a significant relationship with STH infection status $(p<0.05)$

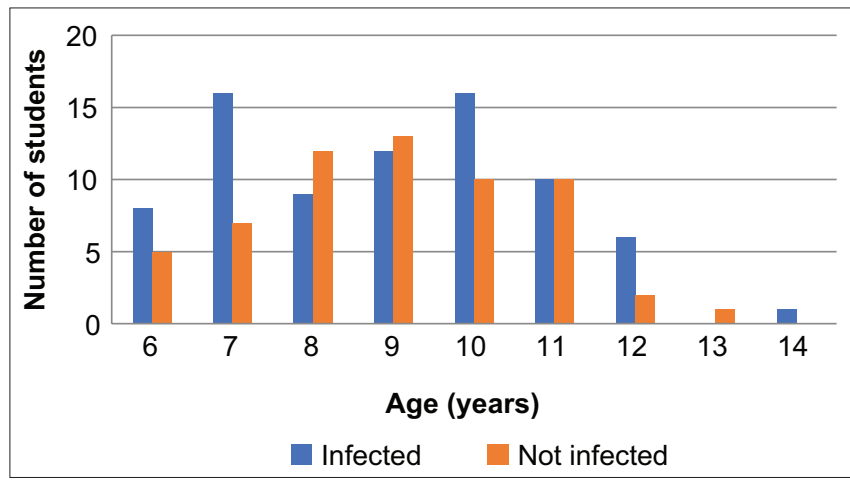

Figure 1: Distribution of STH infection for a specific age

\section{Discussion}

In this study, the prevalence of STH infections was more than half of the population of elementary schoolchildren in Tenganan Village (56.5\%). This figure was higher than the results of other studies conducted in Indonesia [10], [11]. The difference in the prevalence of STH infections in each of these areas is influenced by geographical conditions that support the development of STH, personal hygiene, latrine ownership, economic status, and social culture [12]. 
Table 2: The severity of STH infection

\begin{tabular}{ll}
\hline Helminths found & $\mathrm{n}(\%)$ \\
\hline T. trichiura $(\mathrm{n}=42)$ & $37(88.1)$ \\
$\quad$ Mild & $5(11.9)$ \\
$\quad$ Moderate severe & \\
A. Iumbricoides $(\mathrm{n}=14)$ & $10(71.4)$ \\
$\quad$ Mild & $4(28.6)$ \\
Moderate severe & \\
Both $(\mathrm{n}=22)$ & $10(45.5)$ \\
Mild-mild & $5(22.7)$ \\
Mild-moderate & $4(18.2)$ \\
Moderate-mild & $1(4.5)$ \\
Moderate-moderate & $1(4.5)$ \\
Moderate-severe & $1(4.5)$ \\
Severe-moderate & \\
\hline
\end{tabular}

Similar research by Grimes et al. [13] found that high levels of hygiene correlated with low rates of STH infection in Ethiopia. Another study reported that elementary students who do not wash their hands regularly before eating possessed $98.75 \%$ higher chance of STH infection than those who did wash their hands [14]. This study revealed that handwashing habit before eating, after defecating, and after an outdoor activity has a significant relationship to the prevalence of STH infections.

Table 3: Cross-tabulation between risk factors and infection status

\begin{tabular}{|c|c|c|c|c|c|}
\hline $\begin{array}{l}\text { Risk factors assessed in } \\
\text { the questionnaire }\end{array}$ & $\begin{array}{l}\text { STH-positive } \\
(\mathrm{n}=78)\end{array}$ & $\begin{array}{l}\text { STH-negative } \\
(\mathrm{n}=60)\end{array}$ & $\mathrm{p}$ & $\mathrm{PR}$ & $\mathrm{Cl95 \%}$ \\
\hline \multicolumn{6}{|l|}{ Handwashing before eating } \\
\hline Yes & $15(88.2)$ & $2(11.8)$ & \multirow[t]{2}{*}{0.005} & \multirow[t]{2}{*}{1.695} & \multirow[t]{2}{*}{$1.328-2.162$} \\
\hline No & $63(49.2)$ & $58(50.8)$ & & & \\
\hline \multicolumn{6}{|c|}{ Handwashing after defecating } \\
\hline No & $36(92.3)$ & $3(7.7)$ & \multirow[t]{2}{*}{$<0.001$} & \multirow[t]{2}{*}{2.176} & \multirow[t]{2}{*}{$1.700-2.785$} \\
\hline Yes & $42(42.4)$ & $57(57.6)$ & & & \\
\hline \multicolumn{6}{|c|}{ Direct soil contact during outdoor activities } \\
\hline Yes & $55(73.3)$ & $20(26.7)$ & \multirow[t]{2}{*}{$<0.001$} & \multirow[t]{2}{*}{2.009} & \multirow[t]{2}{*}{$1.411-2859$} \\
\hline No & $23(36.5)$ & 40 (63.5) & & & \\
\hline \multicolumn{6}{|c|}{ Habits of eating snacks while playing outdoor } \\
\hline Yes & $46(93.9)$ & $3(6.1)$ & \multirow[t]{2}{*}{$<0.001$} & \multirow[t]{2}{*}{2.611} & \multirow[t]{2}{*}{$1.961-3.477$} \\
\hline No & $32(36.0)$ & $57(64.0)$ & & & \\
\hline \multicolumn{6}{|c|}{ Handwashing after direct soil contact } \\
\hline No & $48(76.2)$ & $15(23.8)$ & \multirow[t]{2}{*}{$<0.001$} & \multirow[t]{2}{*}{1.905} & \multirow[t]{2}{*}{$1.398-2.596$} \\
\hline Yes & $30(40.0)$ & $45(6.0)$ & & & \\
\hline \multicolumn{6}{|c|}{ Use of footwear while playing outdoor } \\
\hline Yes & $32(86.5)$ & $5(13.5)$ & \multirow[t]{2}{*}{$<0.001$} & \multirow[t]{2}{*}{1.899} & \multirow[t]{2}{*}{$1.481-2.434$} \\
\hline No & $46(45.5)$ & $55(54.5)$ & & & \\
\hline \multicolumn{6}{|c|}{ Takes off shoes during school breaks } \\
\hline Yes & $45(90.0)$ & $5(10.0)$ & \multirow[t]{2}{*}{$<0.001$} & \multirow[t]{2}{*}{2.400} & \multirow[t]{2}{*}{$1.805-3.192$} \\
\hline No & $33(37.5)$ & $55(62.5)$ & & & \\
\hline \multicolumn{6}{|c|}{ Not routinely nail-trimming } \\
\hline Yes & $47(88.7)$ & $6(11.3)$ & \multirow[t]{2}{*}{$<0.001$} & \multirow[t]{2}{*}{2.432} & $1.807-3.271$ \\
\hline No & 31 (36.5) & $54(63.5)$ & & & \\
\hline Nail-biting habits & & & & & \\
\hline Yes & $38(88.4)$ & $5(11.6)$ & $<0.001$ & 2.099 & $1.619-2.721$ \\
\hline No & $40(42.1)$ & $55(57.9)$ & & & \\
\hline Do not possess latrine at & me & & & & \\
\hline Yes & $45(73.8)$ & $16(26.2)$ & $<0.001$ & 1.721 & $1.278-2.319$ \\
\hline No & $33(42.9)$ & $44(57.1)$ & & & \\
\hline
\end{tabular}

We found that handwashing was effective in reducing the number of STH infections, but the WHO still recommends washing hands with soap for 15-20 s. Bali saw an increase in handwashing habits in schoolaged children from $30 \%$ in 2007 to around $60 \%$ in 2013 [15]. However, our study proved that children who wash their hands using water and soap get infected by STH by $67.6 \%$. These differences may be caused by improper handwashing methods. Hence, it is necessary to hold counseling and evaluation of the handwashing technique for these children.

Hookworm infection can occur if it is transmitted by penetrating the skin barrier, one of which is the skin on the sole. The use of footwear when doing outdoor activities is essential as one step to avoid STH infection (especially hookworm) [16]. A study in Ethiopia reported that in 377 children who did not use footwear, $29.2 \%$ were STH-infected [17]. In this study, children who do not use footwear were at risk of being STHinfected 9 times higher than those who do $(p<0.001$, $\mathrm{PR}=1.899, \mathrm{Cl} 95 \%=1.481-2.434)$.

One unhealthy habit in Indonesian children is eating snacks while doing outdoor activities. One study found that children who make such habits were $20 \%$ out of 126 elementary school students [18]. This study found that such practices would have made a significant effect on STH infection. The soil is a medium that is occupied by eggs and STH larvae as part of the life cycle before entering the human body. Hence, soil contact will increase the risk of STH transmission to children if personal hygiene is not properly taken care of.

Another risk factor that significantly influences STH infection status is fingernail hygiene. In this study, elementary schoolchildren who did not trim their nails were regularly and were infected with STH by $88.7 \%$ ( $p<0.001$, PR $=2.432$, Cl95\% $=1.807-$ 3.271 ), and there were $88.4 \%$ of children infected with STH with habit nail-biting habits $(p<0.001$, PR $=2.099$, CI95\% = 1.619-2.721). In STH, worm eggs are an infective form of Ascaris lumbricoides and Trichuris trichuria. Mature eggs on the ground will enter between the nails when in direct contact with the soil and into the mouth when the child puts his hand in his mouth. This habit is usually accompanied by not washing hands properly when eating using hands [17], [19].

Another factor found that significantly influence STH infection status is the availability of latrines. The existence of a restroom is needed to prevent STH infection. In 2013, the use of latrines as a defecation facility in Indonesia reached $76.2 \%$ [20]. Although the results of this research indicate that quite a number of people has private latrines, this study found that the number of residents without private latrines exceeds half $(55.8 \%)$ from the number of respondents. This lack of ownership of latrines has greatly contributed to the transmission of STH in the area. People who do not have a latrine are at risk of being infected by STH 1.7 times higher than those who do have a toilet $(p<0.001$, $\mathrm{Cl} 95 \%=1.278-2 \cdot 319)$.

\section{Conclusion}

The prevalence of STH infections in elementary schoolchildren in Tenganan village was $56.5 \%$. Low personal hygiene and sanitation are risk factors for STH infection that can be overcome; therefore, it is necessary to introduce early prevention efforts in 
elementary schoolchildren as one risk group for STH infection.

\section{References}

1. Ngonjo T, Okoyo C, Andove J, Simiyu E, Lelo AE, Kabiru E, et al. Current status of soil-transmitted helminths among schoo children in Kakamega County, Western Kenya. J Parasitol Res. 2016;2016:1-9. https://doi.org/10.1155/2016/7680124

2. Steinbaum L, Mboya J, Mahoney R, Njenga SM, Null C Pickering AJ. Effect of a sanitation intervention on soiltransmitted helminth prevalence and concentration in household soil: A cluster-randomized controlled trial and risk factor analysis. PLoS Negl Trop Dis. 2019;13(2):e0007180. https://doi. org/10.1371/journal.pntd.0007180

PMid:30742614

3. Savioli L, Albonico M, Daumerie D, Lo NC, Stothard JR, Asaolu S, et al. Review of the 2017 WHO Guideline: Preventive chemotherapy to control soil-transmitted helminth infections in at-risk population groups. An opportunity lost in translation. PLoS Negl Trop Dis. 2018;12(4):e0006296. https://doi.org/10.1371/ journal.pntd.0006296 PMid:29698486

4. Mara D, Lane J, Scott B, Trouba D. Sanitation and health. PLoS Med. 2010;7(11):e1000363. https://doi.org/10.1371/journal. pmed.1000363

PMid:21125018

5. Pasaribu, AP, Alam A, Sembiring K, Pasaribu S, Setiabudi D. Prevalence and risk factors of soil-transmitted helminthiasis among school children living in an agricultural area of North Sumatera, Indonesia. BMC Public Health. 2019;19:1066 https://doi.org/10.1186/s12889-019-7397-6

6. Novianty S, Dimyati Y, Pasaribu S, Pasaribu AP. Risk factors for soil-transmitted helminthiasis in preschool children living in farmland, North Sumatera, Indonesia. J Trop Med. 2018;2018:6706413. https://doi.org/10.1155/2018/6706413

7. Pabalan N, Singian E, Tabangay L, Jarjanazi $H$, Boivin MJ, Ezeamama AE. Soil-transmitted helminth infection, loss of education and cognitive impairment in school-aged children: A systematic review and meta-analysis. PLoS Negl Trop Dis. 2018;12(1):e0005523. https://doi.org/10.1371/journal. pntd.0005523 PMid:29329288

8. Molla E, Mamo H. Soil-transmitted helminth infections, anemia and undernutrition among schools in Yirgacheffee, South Ethiopia. BMC Res Notes. 2018;11(1):585. https://doi. org/10.1186/s13104-018-3679-9

9. Strunz EC, Addiss DG, Stocks ME, Ogden S, Utzinger J, Freeman MC. Water, sanitation, hygiene, and soil-transmitted helminth infection: A systematic review and meta-analysis. PLoS Med. 2014;11(3):e1001620. https://doi.org/10.1371/ journal.pmed.1001620

PMid:24667810
10. Freeman MC, Chard AN, Nikolay B, Garn JV, Okoyo C, Kihara J, et al. Associations between school- and household-level water, sanitation and hygiene conditions and soil-transmitted helminth infection among Kenyan school children. Parasit Vectors. 2015;8:412. https://doi.org/10.1186/s13071-015-1024-x

11. Sanchez AL, Gabrie JA, Usuanlele MT, Rueda MM, Canales M, Gyorkos TW. Soil-Transmitted Helminth infections and nutritional status in school-age children from rural communities in Honduras. PLOS Negl Trop Dis. 2013;7(8):e2378. https://doi. org/10.1371/journal.pntd.0002378

12. Barazesh A, Fouladvand $M$, Tahmasebi R, Heydari A, Kooshesh F. Prevalence of intestinal parasitic infections among primary school children in Bushehr, Iran. Avicenna J Clin Microb Infec. 2017;4:1-6. https://doi.org/10.17795/ajcmi-34335

13. Grimes JE, Tadesse G, Mekete K, Wuletaw Y, Gebretsadik A French MD, et al. School Water, sanitation, and hygiene, soiltransmitted helminths, and schistosomes: National mapping in Ethiopia. PLoS Negl Trop Dis. 2016;10(3):e0004515. https://doi. org/10.1371/journal.pntd.0004515 PMid:26954688

14. Islamudin RA, Suwandono A, Saraswati LD, Putri RK. The Association between Soil Transmitted Helminth Infections with Nutritional Status in Children (A Cross Sectional Study in Elementary School, Candi Village, Semarang District, Central Java Province, Indonesia. The $2^{\text {nd }}$ International Meeting of Public Health; 2018. p. 288-95. https://doi.org/10.18502/kls. v4i4.2288

15. Hirai M, Graham JP, Mattson KD, Kelsey A, Mukherji S, Cronin AA. Exploring determinants of handwashing with soap in Indonesia: A quantitative analysis. Int J Environ Res Public Health. 2016;13(9):868. https://doi.org/10.3390/ijerph13090868 PMid:27598178

16. Silver ZA, Kaliappan SP, Samuel P, Venugopal S, Kang G, Sarkar R, et al. Geographical distribution of soil transmitted helminths and the effects of community type in South Asia and South East Asia a systematic review. PLOS Negl Trop Dis. 2018;12(1):e0006153. https://doi.org/10.1371/journal. pntd.0006153

17. Shumbej T, Belay T, Mekonnen Z, Tefera T, Zemene E. Soiltransmitted helminths and associated factors among pre-school children in Butajira Town, South-Central Ethiopia: A communitybased cross-sectional study. PLoS One. 2015;10:1-11. https:// doi.org/10.1371/journal.pone.0136342 PMid:29346440

18. Wiryadana KA, Putra IW, Rahayu PD, Pradnyana MM, Purwanta ML, Sudarmaja, IM. Risk factors of soil-transmitted helminth infection among elementary school students. Paediatr Indones. 2017;57(6):295-302. https://doi.org/10.14238/pi57.6.2017.1571

19. Sugianto R, Sukarno V, Sudarmaja IM, Swastika IK. Water source as the main risk factor of soil-transmitted helminths infection on primary school students in Antiga village, Bali. Asian J Pharm Clin Res. 2019;12(6):119-21.

20. Suryantari SA, Satyarsa AB, Hartawan IG, Parastuta IK Sudarmaja IM. Prevalence, intensity and risk factors of soil transmitted helminths infections among elementary school students in Ngis village, Karangasem district, Bali. Indones J Trop Infect Di. 2019;7(6):137-43. https://doi.org/10.20473/ijtid. v7i6.9952 